\title{
Pseudomonas fluorescens Biovar V: Its Resolution into Distinct Component Groups and the Relationship of These Groups to Other $P$. fluorescens Biovars, to $P$. putida, and to Psychrotrophic Pseudomonads Associated with Food Spoilage
}

\author{
By ERICKA L. BARRETT, ${ }^{*}$ RAMÓN E. SOLANES, ${ }^{2}$ JANE S. TANG $^{1}$ AND \\ NORBERTO J. PALLERONI ${ }^{3}$ \\ ${ }^{1}$ Department of Food Science, and Technology, University of California, Davis, California 95616, \\ USA \\ ${ }^{2}$ Cátedra de Microbiología, Facultad de Ciencias Agrarias, Universidad Nacional de Cuyo, \\ Mendoza, Argentina \\ ${ }^{3}$ Department of Biology, Virginia Polytechnic Institute and State University, Blacksburg, \\ Virginia 24061, USA
}

(Received 25 March 1986; revised 10 June 1986)

\begin{abstract}
A numerical taxonomic analysis was performed to evaluate the appropriateness of a single biovar designation (biovar V) for all Pseudomonas fluorescens isolates negative for denitrification, levan production and phenazine pigmentation and to determine the relationship of biovar V strains to other taxa within the same Pseudomonas RNA homology group. Seventy-two strains assigned to $P$. fluorescens biovar $\mathrm{V}$ and four strains of $P$. fragi were characterized and the data subjected to a numerical taxonomic analysis along with comparable data for 17 previously characterized strains of this biovar and 89 P. putida strains. Seven distinct biovar V clusters containing three or more strains were revealed, and the carbon sources useful for their differentiation were identified. Cluster 1 (38 strains) closely resembled two atypical $P$. fluorescens I strains. It was also related to $P$. fluorescens biovar IV and to $P$. fragi. Cluster 2 ( 5 strains) was related to cluster 1 . Cluster 3 (7 strains) was identical to a major group of meat spoilage psychrotrophic pseudomonads ( $P$. lundensis). Cluster 4 ( 3 strains) was not related to any other group examined. Cluster 5 consisted of six isolates initially designated $P$. putida A along with four $\boldsymbol{P}$. fluorescens biovar V strains all of which resembled $\boldsymbol{P}$. putida more than they resembled the other $P$. fluorescens groups. Cluster 6 (16 strains) was distinct from the other biovar V clusters, but was closely related to $P$. fluorescens biovars I and II. Cluster 7 ( 3 strains) shared many characteristics with cluster 5. Separate $P$. fluorescens biovar designations are proposed for cluster 6 and for the combined clusters 1 and 2 . A new $P$. putida biovar is proposed for the combined clusters 5 and 7 .
\end{abstract}

\section{INTRODUCTION}

Pseudomonas fluorescens biotype $\mathrm{G}$, now referred to as P. fluorescens biovar V (Palleroni, 1984), had the dubious distinction of being the only unsatisfactory fluorescent biotype delineated by Stanier et al. (1966) in their extensive taxonomic study which became the cornerstone of virtually all subsequent Pseudomonas taxonomy. Biotype G consisted of fluorescent strains which were negative for the three primary characteristics used by Stanier $e t$ al. (1966) for fluorescent biotype assignment, namely levan production, phenazine pigmentation and denitrification. The heterogeneity of the group was revealed in the nutritional studies which, in the case of the other biotypes, had strongly supported biotype assignment as based on the primary characteristics. Because the heterogeneity of the group has precluded the designation of typical strains, representatives of $P$. fluorescens biovar $\mathrm{V}$ have not been included 
in most subsequent studies of the relationships between the several fluorescent biovars (Palleroni et al., 1972, 1973; Champion et al., 1980; Whitaker et al., 1981a, b) or between $P$. fluorescens and other Pseudomonas species (Palleroni \& Doudoroff, 1972; Palleroni et al., 1973; Molin \& Ternström, 1982, 1986; Shaw \& Latty, 1982, 1984).

The exclusion of $P$. fluorescens biovar $\mathrm{V}$ representatives in such studies has not been perceived as a problem because it has generally been thought that this biovar consists primarily of strains which properly belong to other biotypes, but which have lost one or more of the properties considered to be of primary diagnostic importance (Stanier et al., 1966; Palleroni, 1984). However, there is no experimental evidence that favours this hypothesis over the alternative possibility that biovar $\mathrm{V}$ consists of strains quite distinct from the other biovars. The latter possibility is suggested by the report that fluorescent strains which would be assigned to biovar $\mathrm{V}$ using the criteria of Stanier et al. (1966) constitute more than $75 \%$ of the fluorescent soil isolates in at least some areas of the world (Sands \& Rovira, 1971). The primary goal of the work reported here was to address the question of the uniqueness of $P$. fluorescens biovar $V$.

The secondary goal was to examine the relationship of recently characterized pseudomonad food isolates to strains which comprise biovar V. The vast majority of oxidase-positive pseudomonads isolated from meat fall into two groups, both of which resemble $P$. fluorescens in certain respects (Molin \& Ternström, 1982, 1986; Shaw \& Latty, 1982, 1984). The first group contains the type strain of $P$. fragi. Although these strains are not fluorescent, their carbon source utilization matches the 'ideal fluorescent phenotype' outlined by Stanier et al. (1966). Furthermore, Whitaker et al. $(1981 a, b)$ have shown that the allostery of the $P$. fragi phenylalanine biosynthetic enzymes supports assignment to Pseudomonas RNA homology group I, which includes the fluorescent species (Palleroni et al., 1973). The second major group of meat isolates contains fluorescent strains which would have been assigned to biovar $V$ on the basis of the primary characteristics noted above (Molin \& Ternström, 1982, 1986; Shaw \& Latty, 1982, 1984). Molin et al. (1986) proposed separate species designation ( $P$. lundensis) for this group. Numerical taxonomic analyses by both groups of investigators indicated a closer relationship between these two major groups of meat isolates than between either of them and any well-characterized fluorescent biovars. However, representatives of biovar $\mathrm{V}$ were not included in those studies.

\section{METHODS}

Strains. Strains included in the numerical analyses are listed in Table 1. Strains with the prefix RYS were described by Stanier et al. (1966). Strains characterized in this study (prefix PJ) were obtained from Professor Hans Lautrop of the Statens Serum Institut, Copenhagen, Denmark. Four strains of $P$. fragi were included in the numerical analyses: ATCC 4973, ATCC 27362 and ATCC 27363 (from the American Type Culture Collection) and FSBC 9 (from the Department of Food Science collection, originally isolated from cottage cheese). Additional $P$. fragi isolates were obtained by streaking out samples of spoiled cottage cheese or skim milk on nutrient agar (Difco) incubated at $30^{\circ} \mathrm{C}$. Purified isolates which were Gram-negative, polarly flagellated rods and which were oxidase-positive, strictly respiratory, non-pigmented, and capable of growth at $4{ }^{\circ} \mathrm{C}$ were considered presumptive P. fragi.

Characterization methods Bacterial strains were screened for 147 characteristics using the methodology of Stanier et al. (1966). The following characteristics were used by Stanier et al. (1966) but were not included in these studies: Tween 80 and egg yolk reactions, autotrophic growth with hydrogen, number of flagella, and the utilization of methanol, methylamine, oxalate, eicosanedioate, isophthalate, terephthalate, testosterone, $m$ aminobenzoate, $p$-aminobenzoate, $n$-dodecane and $n$-hexadecane. Similarity $\left(S_{J}\right)$ and matching $\left(S_{S_{M}}\right)$ coefficients were calculated and the cluster analyses (group average method) performed using the methods of Sokal \& Sneath (1963). DNA was isolated using the procedure of Marmur (1961) and $G+C$ content determined using the method of Mandel (1966).

\section{RESULTS AND DISCUSSION}

\section{Delineation of clusters comprising $P$. fuorescens biovar $V$}

Seventy-two $P$. fluorescens strains assigned to biovar V on the basis of their lack of phenazine pigments and their inability to denitrify or produce levan were screened along with four $P$. fragi 
Table 1. Strains included in the numerical analyses

\begin{tabular}{|c|c|c|}
\hline Cluster* & Strains & Initial designation $\dagger$ \\
\hline Pf V-1 & $\begin{array}{l}\text { PJ254, PJ259, PJ295, PJ310, PJ387, PJ391, PJ690, PJ700, PJ701, PJ704, } \\
\text { PJ715, PJ760, PJ771, PJ855, PJ856, PJ861, PJ867, PJ835, PJ870, PJ877, } \\
\text { PJ950, PJ952, PJ953, PJ954, PJ955, PJ956, PJ965, PJ977, PJ980, PJ981, } \\
\text { PJ984, PJ985 } \\
\text { RYS164, RYS169, RYS171, RYS172, RYS206, RYS269 }\end{array}$ & P. fluorescens V $\mathrm{V}^{\prime}$ \\
\hline Pf V-2 & PJ277, PJ389, PJ942, PJ958, PJ974 & P. fluorescens V \\
\hline Pf V-3 & PJ63, PJ66, PJ720, PJ727, PJ728, PJ738, PJ899 & P. fluorescens V \\
\hline Pf V-4 & RYS1, RYS99, RYS124 & P. fluorescens $\mathrm{V} \ddagger$ \\
\hline Pf V-5 & $\begin{array}{l}\text { PJ783, PJ873, PJ878, PJ949 } \\
\text { PJ91, PJ98, PJ275, PJ276, PJ892, PJ897 }\end{array}$ & $\begin{array}{l}\text { P. fluorescens } \mathrm{V} \\
\text { P. putida A }\end{array}$ \\
\hline Pf V-6 & $\begin{array}{l}\text { PJ57, PJ68, PJ77, PJ270a, PJ270b, PJ282, PJ329, PJ694, PJ751, PJ836 } \\
\text { RYS33, RYS34, RYS149, RYS166, RYS195, RYS271 }\end{array}$ & $\begin{array}{l}\text { P. fluorescens } \mathrm{V} \\
\text { P. fluorescens } \mathrm{V} \ddagger\end{array}$ \\
\hline Pf $\mathrm{V}-7$ & PJ805, PJ808, PJ940 & P. fluorescens V \\
\hline Pp A & $\begin{array}{l}\text { PJ6, PJ67, PJ80, PJ81, PJ82, PJ88, PJ89, PJ92, PJ93, PJ96, PJ229, PJ235, } \\
\text { PJ242, PJ279, PJ280, PJ303, PJ305, PJ312, PJ324, PJ325, PJ392, PJ399, } \\
\text { PJ498, PJ530, PJ534, PJ542, PJ677, PJ698, PJ726, PJ750, PJ768, PJ777, } \\
\text { PJ780, PJ790, PJ891, PJ992, PJ997, PJ999 } \\
\text { RYS5, RYS6, RYS7, RYS26, RYS42, RYS43, RYS44, RYS49, RYS51, } \\
\text { RYS56, RYS76, RYS77, RYS82, RYS87, RYS89, RYS90, RYS100, } \\
\text { RYS111, RYS115, RYS118, RYS119, RYS122, RYS128, RYS130, } \\
\text { RYS144, RYS145, RYS154, RYS160, RYS266, RYS276 }\end{array}$ & P. putida A \\
\hline Pp B & $\begin{array}{l}\text { PJ707, PJ874, PJ948, PJ951, PJ961, PJ991 } \\
\text { PJ994 } \\
\text { PJ770 } \\
\text { RYS53, RYS96, RYS107, RYS110, RYS153, RYS157, RYS158, RYS167 }\end{array}$ & $\begin{array}{l}\text { P. putida } \mathrm{B} \S \\
P . \text { putida } \mathrm{A} \\
P . \text { fluorescens } \mathrm{V} \\
P \text {. putida } \mathrm{B} \ddagger\end{array}$ \\
\hline P fr & ATCC 4973, ATCC 27362, ATCC 27363, FSB 9 & P. fragi \\
\hline (None) & $\begin{array}{l}\text { PJ724, PJ725, PJ758, PJ797, PJ893, PJ946, PJ962, PJ978, PJ982, PJ995 } \\
\text { PJ90, PJ94, PJ95, PJ983, PJ993 } \\
\text { RYS267, RYS272 } \\
\text { RYS8 } \\
\text { RYS98 }\end{array}$ & 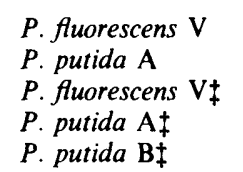 \\
\hline
\end{tabular}

* Strains are arranged by cluster as shown in Fig. 1. Notations: Pf V, P. fluorescens biovar V; Pp A, P. putida biovar A; Pp B, P. putida biovar B; P fr, P. fragi.

$\dagger$ Initial designations of $P J$ strains based on gelatin liquefaction, pigmentation, levan production and ability to denitrify. Strains were characterized in this study unless otherwise indicated.

$\ddagger$ Strains characterized by Stanier et al. (1966).

$\S$ Strains characterized by Champion et al. (1980).

strains with respect to 147 characters (Stanier et al., 1966). Preliminary results revealed that several strains resembled $P$. putida in their nutritional spectrum; like $P$. fluorescens $\mathrm{V}$ and $P$. fragi, $P$. putida consists of strains negative for phenazine pigments, denitrification and levan production. To enable recognition of $P$. fluorescens biovar $\mathrm{V}$ clusters which might be more correctly designated $P$. putida, it was thus necessary to include as many $P$. putida strains as possible in our numerical taxonomic analysis. A total of $49 P$. putida strains were characterized. In the subsequent analyses, these results for all strains were pooled with the comparable data of Stanier et al. (1966) for 'biotype G' (17 strains), $P$. putida biovar A (32 strains), and P. putida biovar B (9 strains), plus the data of Champion et al. (1980) for an additional six $P$. putida B strains. Similarity coefficients were calculated for all pairs and a phenogram was constructed using the group average method (Fig. 1).

The biovar V strains formed seven distinct clusters of three or more strains at the $77 \% S_{J}$ level. $\boldsymbol{P}$. fragi, $\boldsymbol{P}$. putida A and $\boldsymbol{P}$. putida $\mathrm{B}$ also formed distinct clusters at or above this level. Clusters V-1, V-2, V-3, and $P$. fragi were united at $71 \% S_{J}$ along with four other biovar V strains (PJ962, PJ978, PJ946, PJ995) and two strains initially assigned to P. putida A (PJ94 and PJ95). At 72\% 


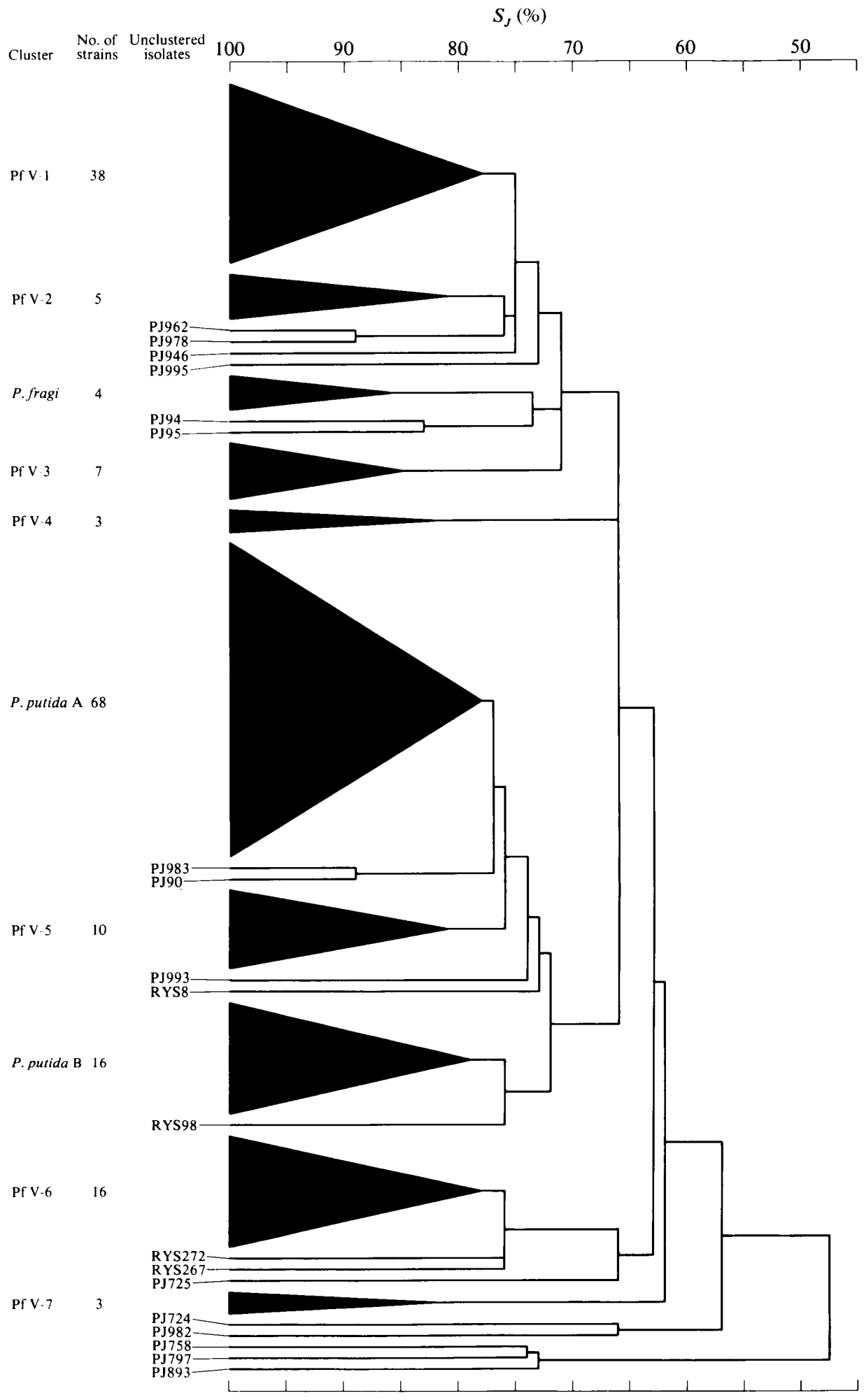

Fig. 1. Simplified phenogram based on the group average method analysis of a similarity matrix derived from the $S_{J}$ coefficient. $P$. fiuorescens biovar $\mathrm{V}$ clusters are designated as $\mathrm{Pf} \mathrm{V}$. 
$S_{J}$, cluster V-5 was united with $P$. putida A, $P$. putida B and five single $P$. putida strains (PJ90, PJ983, PJ993, RYS8, RYS98). The two large taxa joined each other and cluster V-4 at $66 \% S_{J}$. Clusters V-6 and V-7 appeared to be only distantly related to the above groups; cluster V- 6 was joined by three single biovar V strains (RYS267, RYS272 and PJ725) before joining the rest at $63 \% S_{J}$ and cluster V-7 joined at $62 \% S_{J}$. Five $P$. fluorescens biovar V strains joined all the rest at $S_{J}$ levels below 60\% (PJ724, PJ982, PJ758, PJ797, PJ893).

Most of the PJ strains included in our analysis were previously examined by Jessen (1965), who subdivided a large collection of fluorescent pseudomonads into 82 biotypes using primarily acid production from various carbohydrates. Our cluster analysis shows significant agreement with Jessen's biotype assignments for the same strains. For example, Jessen's biotypes 18, 21 and 25-28 contained the PJ cluster V-1 strains, and his biotypes 10, 46 and 47 consisted of the cluster V-5, V-7 and V-3 strains, respectively.

The carbon sources useful for the differentiation of the various clusters are shown in Table 2. Previously characterized fluorescent pseudomonad groups are also included in this table for comparison. They are divided into the clusters revealed by Champion et al. (1980), who used the same phenotypic characters as were used in this study. The remaining carbon sources tested which do not appear in this table apparently contributed little to the clustering based on all characteristics as they fell into one of three classes: $(a)$ used by no strains or used by very few strains, none of which constituted more than $20 \%$ of any cluster (D-fucose, L-rhamnose, cellobiose, lactose, maltose, starch, inulin, salicin, pimelate, poly- $\beta$-hydroxybutyrate, maleate, $\mathrm{D}(-)$ tartrate, glycollate, ethylene glycol, isopropanol, geraniol, D-mandelate, L-mandelate, $o$ hydroxybenzoate, $m$-hydroxybenzoate, phenylethanediol, phthalate, naphthalene, phenol, $L-$ threonine, L-norleucine, DL- $\alpha$-aminobutyrate, DL- $\alpha$-aminovalerate, D-tryptophan, acetamide, pantothenate, $n$-dodecane and $n$-hexadecane); (b) used by most strains of all clusters (D-glucose, D-fructose, D-ribose, gluconate, 2-ketogluconate, acetate, propionate, caproate, heptanoate, caprylate, pelargonate, caprate, succinate, glutarate, fumarate, L-malate, DL-lactate, DL- $\beta$ hydroxybutyrate, DL-glycerate, citrate, 2-oxoglutarate, pyruvate, aconitate, glycerol, L- $\alpha$ alanine, $\mathrm{D}$ - $\alpha$-alanine, $\beta$-alanine, L-leucine, L-isoleucine, L-valine, L-aspartate, L-glutamate, Larginine, L-ornithine, L-histidine, L-proline, L-tyrosine, $\gamma$-aminobutyrate, $\delta$-aminovalerate, putrescine, spermine, betaine and sarcosine); or (c) used by many strains in one or more clusters, but of little diagnostic value (D-mannose, sucrose, butyrate, isobutyrate, valerate, isovalerate, azelate, suberate, D-malate, $\mathrm{L}(+)$ tartrate, meso-tartrate, citraconate, laevulinate, butanol, isobutanol, butylene glycol, benzoate, L-serine, L-lysine, L-citrulline, L-phenylalanine and ethanolamine). Utilization patterns for the latter group of carbon sources are shown in Table 3.

All strains were positive for motility and oxidase reaction and were negative for denitrification, levan production, phenazine pigmentation, growth at $41^{\circ} \mathrm{C}$ and poly- $\beta$ hydroxybutyrate accumulation. Strains of all clusters formed fluorescent pigment with the exception of one strain in cluster V-5 and three $P$. putida strains. Results for gelatin liquefaction and ability to grow at $4^{\circ} \mathrm{C}$ are shown in Table 3 .

\section{Relationship of $P$. fluorescens $V$ clusters to other fluorescent biovars}

By definition, $P$. fluorescens $\mathrm{V}$ consists of $P$. fluorescens strains which are negative for denitrification, levan production and phenazine pigmentation while all other $P$. fluorescens biovars consist of strains positive for one or more of those characteristics (Stanier et al., 1966; Palleroni, 1984). It was suggested previously (Stanier et al., 1966) that $P$. fluorescens biovar V may consist of strains which, on the basis of overall phenotype, more closely resemble strains of other biovars than each other, but which have lost one or more of the aforementioned primary traits. If this were the case, then the respective nutritional spectra of the various biovar $\mathrm{V}$ clusters should each parallel that of another fluorescent group which is positive for one or more of the primary traits. This hypothesis can be tested by comparing the carbon source utilization data for the biovar $\mathrm{V}$ clusters with the patterns for other fluorescent groups. To permit quantification of the comparison, an additional numerical analysis was performed: matching coefficients $\left(S_{S M}\right)$ were calculated for all pairs of strains with respect to the carbon sources listed in Table 2. Two additional carbon sources important in differentiation among the other 


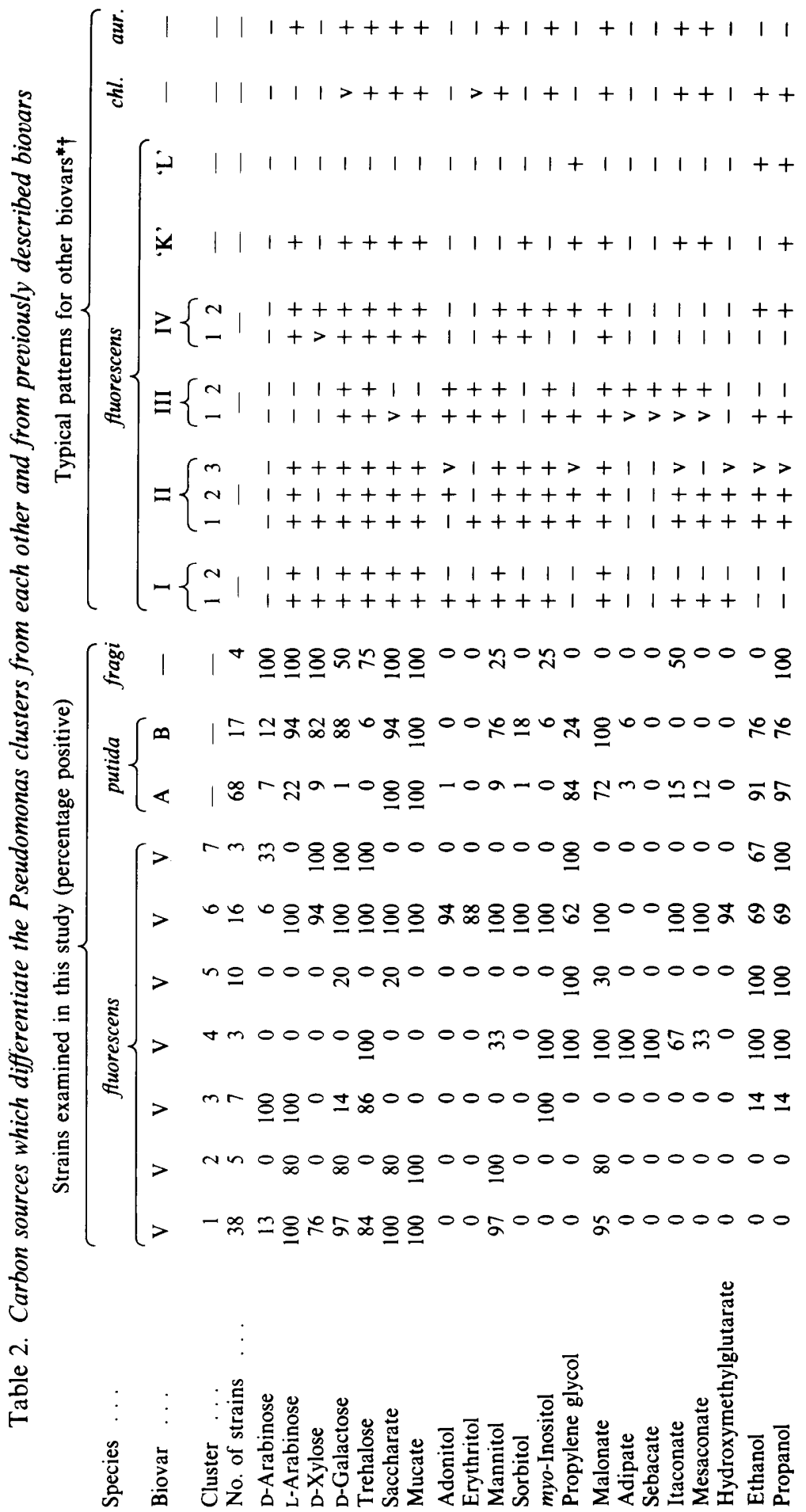




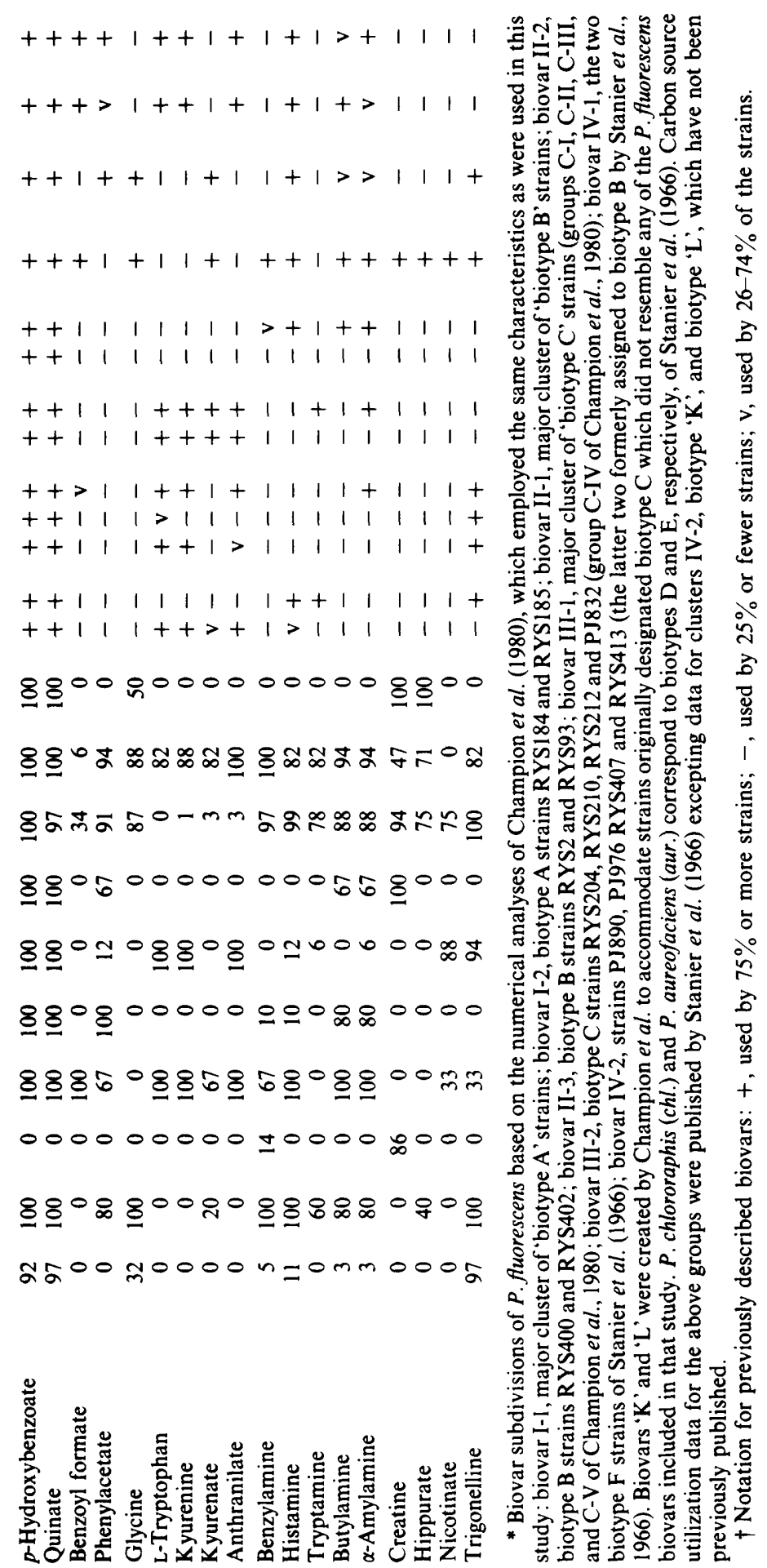


Table 3. Additional characteristics for which strains of $P$. fluorescens biovar $V$ differ

\begin{tabular}{|c|c|c|c|c|c|c|c|c|c|c|}
\hline \multirow{3}{*}{$\begin{array}{l}\text { Species } \ldots \\
\text { Biovar } \ldots\end{array}$} & \multicolumn{10}{|c|}{ Strains examined in this study (percentage positive) } \\
\hline & \multicolumn{7}{|c|}{ fluorescens } & \multicolumn{2}{|c|}{ putida } & \multirow{2}{*}{$\begin{array}{c}\text { fragi } \\
-\end{array}$} \\
\hline & V & $\mathrm{V}$ & V & V & V & V & V & A & B & \\
\hline Cluster ... & 1 & 2 & 3 & 4 & 5 & 6 & 7 & - & - & - \\
\hline No. of strains & 38 & 5 & 7 & 3 & 10 & 16 & 3 & 68 & 17 & 4 \\
\hline Mannose & 92 & 100 & 43 & 33 & 10 & 94 & 100 & 26 & 82 & 100 \\
\hline Sucrose & 45 & 0 & 0 & 33 & 0 & 6 & 0 & 4 & 7 & 0 \\
\hline Butylene glycol & 11 & 0 & 0 & 67 & 90 & 56 & 100 & 71 & 47 & 0 \\
\hline Butyrate & 45 & 100 & 100 & 100 & 100 & 38 & 67 & 97 & 100 & 100 \\
\hline Isobutyrate & 74 & 80 & 100 & 33 & 100 & 50 & 67 & 94 & 87 & 100 \\
\hline Valerate & 89 & 100 & 100 & 100 & 100 & 56 & 67 & 100 & 100 & 100 \\
\hline Isovalerate & 87 & 100 & 100 & 100 & 100 & 38 & 67 & 100 & 100 & 75 \\
\hline Suberate & 0 & 0 & 0 & 33 & 0 & 0 & 0 & 0 & 0 & 0 \\
\hline Azelate & 0 & 0 & 0 & 67 & 0 & 0 & 0 & 0 & 0 & 0 \\
\hline D-Malate & 60 & 60 & 86 & 0 & 100 & 31 & 100 & 66 & 53 & NT \\
\hline $\mathrm{L}(+)$ Tartrate & 0 & 0 & 0 & 0 & 0 & 6 & 0 & 49 & 12 & NT \\
\hline meso-Tartrate & 50 & 20 & 0 & 0 & 80 & 94 & 67 & 57 & 0 & NT \\
\hline Citraconate & 29 & 80 & 0 & 0 & 0 & 62 & 0 & 6 & 65 & 0 \\
\hline Laevulinate & 45 & 40 & 0 & 33 & 40 & 19 & 0 & 35 & 67 & 0 \\
\hline Butanol & 24 & 0 & 29 & 100 & 100 & 50 & 100 & 94 & 82 & 100 \\
\hline Isobutanol & 8 & 0 & 29 & 67 & 100 & 56 & 0 & 97 & 71 & 75 \\
\hline Benzoate & 29 & 100 & 71 & 100 & 20 & 81 & 0 & 100 & 100 & 50 \\
\hline L-Serine & 100 & 80 & 71 & 33 & 70 & 100 & 33 & 81 & 80 & 0 \\
\hline L-Lysine & 82 & 60 & 86 & 100 & 100 & 81 & 100 & 100 & 82 & 75 \\
\hline Citrulline & 26 & 40 & 0 & 100 & 100 & 69 & 0 & 91 & 35 & 100 \\
\hline L-Phenylalanine & 97 & 100 & 57 & 33 & 100 & 69 & 100 & 97 & 94 & 100 \\
\hline Ethanolamine & 74 & 40 & 71 & 100 & 100 & 62 & 100 & 74 & 24 & 25 \\
\hline Gelatin liquefaction & 92 & 100 & 71 & 100 & 40 & 81 & 0 & 0 & 18 & 0 \\
\hline Growth at $4^{\circ} \mathrm{C}$ & 100 & 100 & 100 & 100 & 80 & 100 & 100 & 13 & 100 & 100 \\
\hline
\end{tabular}

NT, Characteristics not tested.

fluorescent biovars were also included in this analysis: propionate (uniquely negative for $P$. fluorescens biovar IV), and sucrose (negative for biovar III but positive for all other $P$. fluorescens biovars). For each pair of clusters to be compared, the $S_{S M}$ values which related, respectively, each member of the one cluster to each member of the other cluster were averaged. The internal homogeneity of each group was also evaluated by calculation of the average $S_{S M}$ between all pairs within it. The results are compiled in Fig. 2.

The analysis revealed significant similarity of $P$. fluorescens $\mathrm{V}-1$ to $P$. fluorescens $\mathrm{I}-2$ (average $S_{S M}=89 \%$ ). In contrast, the average $S_{S M}$ relating the I-2 strains to the major group within their own biovar ( $P$. fluorescens I-1) was $67 \%$. Apparently on the basis of carbon source utilization, biovar I-2 strains would be more correctly assigned to biovar V. However, the two biovar I-2 strains do produce levan from sucrose (Stanier et al., 1966), which is the primary characteristic used to differentiate biovar I strains from biovar V strains. Close similarity was also revealed between cluster V-1 and the two $P$. fluorescens IV-1 strains (average $S_{S M}=85 \%$ ). The biovar IV-1 strains were both originally designated $P$. lemonnieri and were described as producing a blue insoluble phenazine pigment, although the pigment production has proved to be an unstable characteristic (Stanier et al., 1966). Both denitrify and produce levan from sucrose, and thus differ from biovar V strains on the basis of all three primary characteristics used for biovar assignment. Molin \& Ternström (1986) described a cluster of $P$. fluorescens strains isolated from soil which were readily assigned to biovar IV on the basis of carbon source utilization, but many of which did not denitrify, produce levan, or form a blue pigment. Perhaps their group is synonymous with our cluster V-1.

There have been other situations in which the ability to denitrify was found not to correlate 


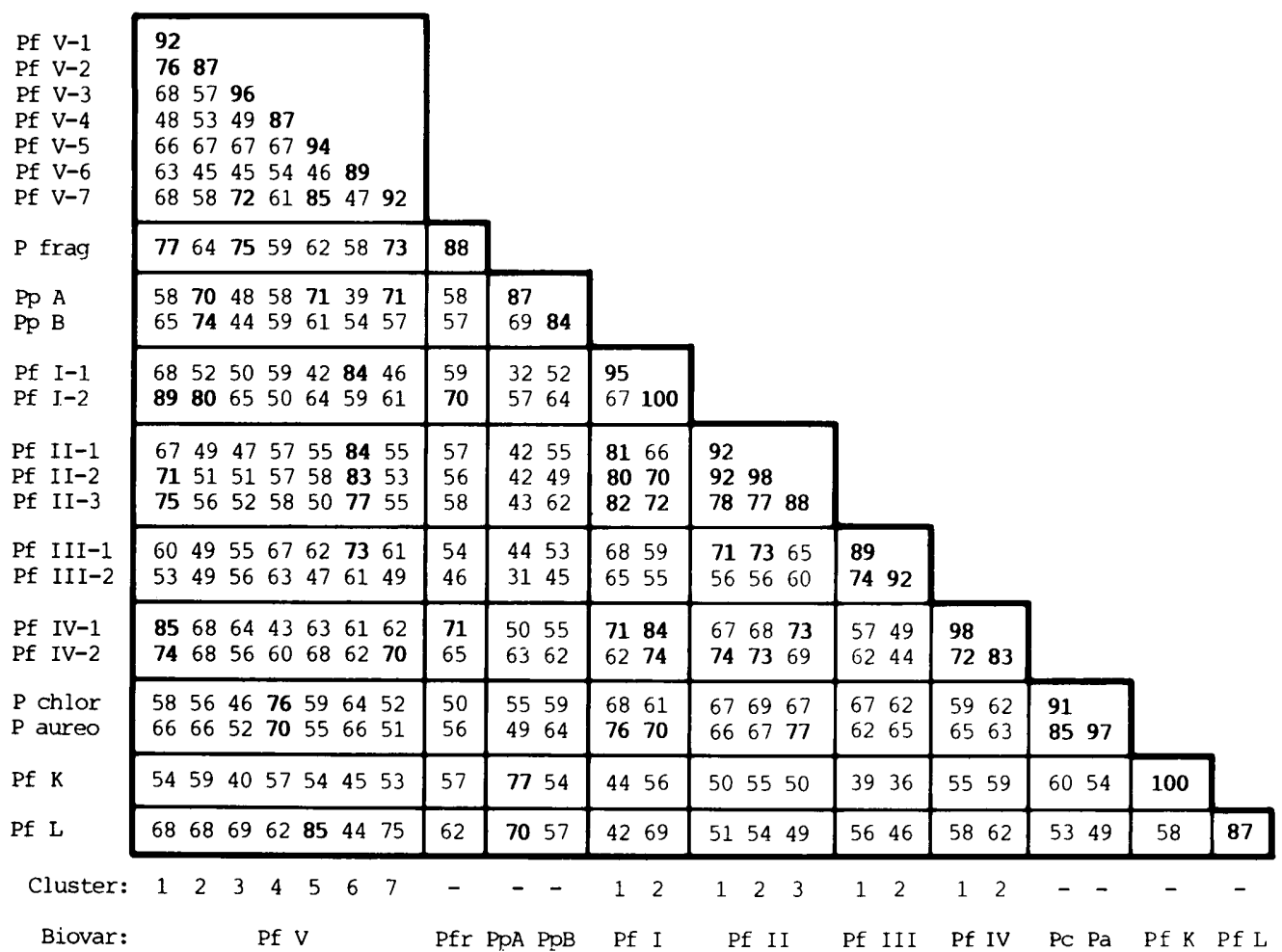

Fig. 2. Average matching coefficients $\left(S_{S M}\right)$ between fluorescent pseudomonad clusters with respect to the carbon sources listed in Table 2. Pf, $P$. fluorescens; $\mathrm{P}$ frag and Pfr, P. fragi; Pp, P. putida; $\mathrm{P}$ chlor and $\mathrm{Pc}, P$. chlororaphis; $\mathrm{P}$ aureo and $\mathrm{Pa}, P$. aureofaciens; $\mathrm{Pf} \mathrm{K}$ and $\mathrm{Pf} \mathrm{L}, P$. fluorescens biovars $\mathrm{K}$ and $\mathrm{L}$, respectively, as defined by Champion et al. (1980). Biovars and subgroups are as defined in the footnotes to Table 1 .

with other phenotypic traits. Champion et al. (1980) showed that a number of fluorescent strains assigned to biotype C (biovar III) on the basis of their ability to denitrify showed more overall phenotypic similarity with strains of $\boldsymbol{P}$. putida biotype B (biovar II), which, by definition, is a non-denitrifying group. Similarly Doudoroff et al. (1974) presented evidence supporting the abandonment of the specific name $P$. denitrificans; their results showed that strains bearing this name constituted several different species and at least two genera.

The nutritional spectrum of $P$. fluorescens V-1 was also shown to resemble that of $P$. fragi. Previous studies of $P$. fragi have not revealed a close relationship between this species and $P$. fluorescens (Molin \& Ternström, 1982, 1986; Shaw \& Latty, 1982), but biovar V was not included in those studies.

Cluster V-3 was distinct from the other fluorescent groups but did show some resemblance to $P$. fragi. Its limited range of carbon sources (Table 2) was reminiscent of the recently described group of meat spoilage pseudomonads some representatives of which were fluorescent, namely 'cluster 2' of Molin \& Ternström (1982) and 'cluster 3' of Shaw \& Latty (1982), which has since been named $P$. lundensis (Molin et al., 1986). An examination of the reported carbon source utilization pattern of the meat isolates with respect to the carbon sources listed in Table 2 revealed that the pattern was virtually identical to that of the $P$. fluorescens V-3 cluster. In the numerical taxonomic analysis of Molin \& Ternström (1986), P. lundensis strains formed a 'supercluster' with strains of $P$. fragi, while $P$. fluorescens biovars I, II, III, and IV formed a separate 'supercluster'. This differs from the picture presented here in which cluster V-3 and $P$. fragi join with cluster V-1 (closely related to biovar IV) before joining with the cluster V-6 (most closely related to biovars I and II, as noted below). 
The $P$. fluorescens V-5 cluster, which consists of strains initially designated $P$. putida A as well as $P$. fluorescens $\mathrm{V}$ strains, was found to resemble $P$. putida A more than any biovar of $P$. fluorescens. None of the V-5 strains used trehalose; Stanier et al. (1966) noted that trehalose was used by virtually all strains of $P$. fluorescens, but no strains of $P$. putida. Cluster V-5 also closely resembled the 'biotype L' strains of Champion et al. (1980). A separate biotype status was proposed for these strains in the latter study because they differed significantly from all the other $P$. fluorescens strains examined. However, $P$. putida strains were not included in that study.

The results compiled in Fig. 2 also revealed that the three strains constituting $P$. fluorescens biovar V-7 were very similar to the biovar V-5 and 'biotype L' strains, although they differed from the V-5 strains with respect to the utilization of trehalose. The relationship between V-5 and V-7 was not revealed in the phenogram (Fig. 1). A review of the $S_{J}$ values used to construct that phenogram indicated that the apparent discrepancy was a result of the method of phenogram construction; the average $S_{J}$ relating the V-7 strains to cluster V-5 by itself was $72 \%$. They were not joined at this $S_{J}$ level because cluster V-5 was more related to P. putida A $\left(S_{J}=75 \%\right.$ ). However, the average $S_{J}$ relating V-7 to $P$. putida A was very low (61\%), so that when it was joined to the combined V-5/P. putida A cluster (68 $P$. putida A strains and 10 cluster V-5 strains), the average $S_{J}$ was only $62 \%$, and the V-5/V-7 relationship was thus obscured. On the other hand, a two-dimensional array such as that shown in Fig. 2 does not obscure relationships between two groups when only one of them is more closely related to a third group.

The $P$. fluorescens biovar V cluster V-6 was found to be closely related to $P$. fluorescens biovars I and II $\left(84 \% S_{S M}\right.$ with biovar I-1, and $84 \%, 83 \%$ and $77 \%$ with II-1, II-2 and II-3, respectively). Biovar I and II strains all form levan from sucrose; strains of biovar II, but not I, also denitrify. There are very few carbon sources that distinguish biovar I strains from biovar II strains. Similarly, we found very few that distinguished most biovar V-6 strains from either I-1 or II strains. In fact, two V-6 strains (PJ77 and PJ270a) were related to each of three $P$. fluorescens biovar II strains (RYS406, RYS411 and RYS414) by an $S_{S M}$ of $95 \%$.

Cluster V-4 was not found to be closely related to any other group examined, its closest relative being $P$. chlororaphis with an average $S_{S M}$ of $76 \%$. However, the relationship of the cluster V-4 strains to the other groups did not appear to parallel the relationship of $P$. chlororaphis to the same groups.

\section{Relationships between biovar $V$ clusters and other 'unassigned' fluorescent strains}

In the first numerical analysis, based on $S_{J}$ values, five $P$. fluorescens biovar $\mathrm{V}$ strains were less than $60 \%$ related to any cluster (PJ724, PJ982, PJ758, PJ797 and PJ893). To see if any of them resembled any of the other groups with respect to the 41 carbon sources used for the second numerical analysis, $S_{S M}$ values relating these strains to the members of all the groups included in Fig. 2 were calculated. Two (PJ724 and PJ982) were found to resemble cluster V-1; each had an average $S_{S M}$ relating them to the $\mathrm{V}-1$ strains greater than $80 \%$. The other three (PJ758, PJ797 and PJ893) were even more closely related to cluster V-3; for each the average $S_{S M}$ relating it to the seven V-3 strains was greater than $88 \%$. The apparent discrepancy between these results and those represented in Fig. 1 is a reflection of the different methods used for the respective cluster analyses. In the initial study, $S_{J}$ values were used; thus only positive results were taken into account. When a cluster is characterized by a limited range of possible carbon sources, as is cluster V-3, the differences between component strains are magnified as compared to differences among members of a group of versatile strains. Matching coefficients were not used in that analysis because the strains shared many negative characteristics, a feature which increases the percentage similarity among all strains, thereby compressing the range of significant differences between clusters. Furthermore, the second analysis involved only those carbon sources which were especially useful for cluster definition. While this selection of carbon sources might be looked upon as deliberate bias, it is important to remember that the clusters on which we were attempting to focus were exactly those clusters revealed in the analysis involving all 147 characteristics.

The carbon sources listed in Table 2 were also used as a basis for examining the 11 'unassigned' fluorescent strains in the original taxonomic work of Stanier et al. (1966) for 
possible overlap with the biovar V clusters. Four of them, RYS17, RYS47, RYS59 and RYS91, were found to be closely related to the V-5 cluster; the average $S_{S M}$ relating each to all the V-5 strains was greater than $85 \%$, and one of them (RYS91) was related to a V-5 strain (PJ783) by an $S_{S M}$ of $100 \%$. Two of Stanier's unassigned strains (RYS10 and RYS127) were related to several V-1 strains by $S_{S M}$ values greater than $80 \%$. The remaining five strains did not appear related to any of the groups examined in this study.

\section{Relationship between P. fragi and P. fluorescens biovar $V$}

In the early descriptions of $P$. fragi, the chief identifying characteristics were the production of 'fruity' spoilage odour (Hussong \& Long, 1937; Morrison \& Hammer, 1941) and the formation of an 'acid ring' in litmus milk (Hussong \& Long, 1937). Although neither characteristic lends itself to accurate strain identification, it has been shown that the type strain deposited many years ago in the American Type Culture Collection is representative of a large and unique class of meat spoilage pseudomonads (Molin \& Ternström, 1982, 1986; Shaw \& Latty, 1982). Like biovar V strains, $P$. fragi neither denitrifies nor produces levan from sucrose. Arginine dihydrolase was positive for all four strains as it is for all the fluorescent pseudomonads tested by Stanier et al. (1966). The G + C content of the three ATCC strains was found to be $58 \cdot 3-58 \cdot 5 \mathrm{~mol}$ $\%$. This value is at the lower limit for $P$. fluorescens (Mandel, 1966). The fluorescent biovars at the lowest end are, in fact, the ones closest to $P$. frag $i$ in our phenotypic analysis, namely biovar IV and strains of biovar V which fell into cluster 1 (Mandel, 1966).

The results of our carbon source utilization tests agreed closely with the comparable results reported by Molin \& Ternström $(1982,1986)$ and Shaw \& Latty (1982) for their major cluster of meat spoilage pseudomonads. About 130 carbon sources included in this study were also used by Molin \& Ternström $(1982,1986)$; our results differed only with respect to the utilization of butyrate, isobutyrate, propanol, butanol and citrulline, all of which we scored as positive, but which were reported as negative by the other investigators. We also examined $20 \mathrm{Gram}$-negative motile rods isolated from separate spoiled dairy products and found seven which closely resembled the named strains of $P$. fragi in carbon source utilization pattern. This indicates that the same species is common in dairy products as well as in meat. All the $P$. fragi strains failed to grow at $37^{\circ} \mathrm{C}$, which may be a useful distinguishing characteristic.

The analyses revealed close relationships between $P$. fragi and $P$. fluorescens clusters $V-1$ and V-3. We had found the latter group to be synonymous with the second major group of meat spoilage pseudomonads, now designated P. lundensis (Molin et al., 1986). Molin \& Ternström $(1982,1986)$ found $P$. fragi to be more closely related to $P$. lundensis than any $P$. fluorescens biovars, but biovar $\mathrm{V}$ was not included in those studies.

\section{Taxonomic conclusions}

The foregoing results have shown that the currently defined $P$. fluorescens biovar $\mathrm{V}$ consists of several distinct groups, most of which are as different from each other on the basis of overall phenotype as are the recognized $P$. fluorescens biovars. The results suggest the need to redefine biovar $\mathrm{V}$ in terms of just one of the clusters revealed in this study and to designate at least two new fluorescent biovars for the other clusters. We propose that cluster V-6 alone should retain the designation biovar $\mathrm{V}$ because it contains the greatest number of the original 'biotype $\mathrm{G}$ ' strains of Stanier et al. (1966). This newly defined biovar $\mathrm{V}$ is part of a group of closely related biovars that includes I and II.

The largest biovar V cluster, V-1, was quite distinct from cluster V-6 and should be designated as a new biovar (biovar VI) which also includes the $P$. fluorescens I-2 strains (RYS184 and RYS185). Because the small number of V-2 strains available for this study does not warrant separate biovar designation at this time, and because this cluster was closely related to $\mathrm{V}-1$, the V-2 strains could also be included in biovar VI for the time being.

An additional new fluorescent biovar is also suggested for cluster V-5. Because it was more related to $P$. putida A than to any $P$. fluorescens group, it should be designated as a $P$. putida biovar, presumably biovar $\mathrm{C}$. The fact that many fluorescent strains which, in previous studies, could not be assigned to one of the established biovars, were shown here to have the V-5 
phenotype supports the recognition of this group as a unique biovar. Cluster V-7 was related to $\mathrm{V}-5$ in the second numerical analysis (Fig. 2) and thus might be considered a subgroup of $\boldsymbol{P}$. putida $\mathrm{C}$ until more strains are available for further study.

Cluster V-3 was shown to be identical to the group of meat isolates now designated $P$. lundensis (Molin et al., 1986). The latter investigators have described the new species in sufficient detail to permit its differentiation from the other fluorescent groups.

Cluster V-4 did not closely resemble any of the other groups examined, but its small size argues against designation of a new biovar at this time. Studies of additional similar strains are needed to clarify the taxonomic position of this cluster.

The results concerning $P$. fragi, like those of previous investigators (Molin \& Ternström, 1982, 1986; Shaw \& Latty, 1982, 1984), support the designation of this group as a unique (and now well-defined) Pseudomonas species. The similarity of $P$. fragi to $P$. fluorescens $V-1$ supports the suggestion that it is part of RNA homology group I (Whitaker et al., 1981 a,b). Perhaps its phenotype is indicative of the lack of the need for fluorescent pigmentation for survival in the rich environment of meats and other foods.

The foregoing studies were initiated under the direction of the late Michael Doudoroff, whose criticisms always turned out to be constructive and inspirational in the long run. The initial studies were supported by Public Health Service grant AI-1808 from the National Institute of Allergy and Infectious Diseases. The remaining work was supported in part by funds from the California Agricultural Experiment Station. We thank John Boyland for his help in designing the computer programs and Richard Bradford for his technical artistry.

We wish to dedicate this paper to Dr Luis F. Leloir on the occasion of his 80th birthday.

\section{REFERENCES}

Champion, A. B., Barrett, E. L., Palleroni, N. J., SoderberG, K. L., Kunisawa, R., Contopoulou, R., Wilson, A. C. \& DOUdOROFF, M. (1980). Evolution in Pseudomonas fluorescens. Journal of General Microbiology 120, 485-511.

Doudoroff, M., Contopoulou, R., Kunisawa, R. \& Palleroni, N. J. (1974). Taxonomic validity of Pseudomonas denitrificans: request for an opinion. International Journal of Systematic Bacteriology 24, 294-300.

HuSSONG, R. V. \& LoNG, H. F. (1937). Classification of the organisms important in dairy products. Iowa Experiment Station Research Bulletin 225, 119-136.

JESSEN, O. (1965). Pseudomonas aeruginosa and Other Green Fluorescent Pseudomonads. A Taxonomic Study. Copenhagen: Munksgaard.

MANDEL, M. (1966). Deoxyribonucleic acid base composition in the genus Pseudomonas. Journal of General Microbiology 43, 272-292.

MARMUR, J. (1961). A procedure for the isolation of deoxyribonucleic acid from microorganisms. Journal of Molecular Biology 3, 208-218.

Molin, G. \& TeRnström, A. (1982). Numerical taxonomy of the psychrotrophic pseudomonads. Journal of General Microbiology 128, 1249-1264.

Molin, G. \& Ternström, A. (1986). Phenotypically based taxonomy of psychrotrophic Pseudomonas isolated from spoiled meat, water, and soil. International Journal of Systematic Bacteriology 36, 257-274

Molin, G., Ternström, A. \& Ursing, J. (1986). Pseudomonas lundensis, a new bacterial species isolated from meat. International Journal of Systematic Bacteriology 36, 339-342.

MORRISON, H. B. \& HAMMER, B. W. (1941). Distribution of Pseudomonas fragi. Journal of Dairy Science 24, 9-18.
Palleroni, N. J. (1984). Pseudomonas. In Bergey's Manual of Systematic Bacteriology, vol. 1, pp. 141199. Edited by N. R. Krieg. Baltimore: Williams \& Wilkins.

Palleroni, N. J. \& Doudoroff, M. (1972). Some properties and taxonomic subdivisions of the genus Pseudomonas. Annual Review of Phytopathology 10, 73-100.

Palleroni, N. J., Ballard, R. W., Ralston, E. \& Doudoroff, M. (1972). Deoxyribonucleic acid homologies among some Pseudomonas species. Journal of Bacteriology 110, 1-11.

Palleroni, N. J., Kunisawa, R., Contopoulou, R. \& DoudorofF, M. (1973). Nucleic acid homologies in the genus Pseudomonas. International Journal of Systematic Bacteriology 23, 333-389

Sands, D. C. \& Rovira, A. D. (1971). Pseudomonas fluorescens biotype $\mathrm{G}$, the dominant fluorescent pseudomonad in South Australian soils and wheat rhizospheres. Journal of Applied Bacteriology 34, 261275.

Shaw, B. G. \& LatTy, J. B. (1982). A numerical taxonomic study of Pseudomonas strains from spoiled meat. Journal of Applied Bacteriology 52, 219228.

Shaw, B. G. \& Latty, J. B. (1984). A study of the relative incidence of different Pseudomonas groups on meat using a computer assisted identification technique employing only carbon source tests. Journal of Applied Bacteriology 57, 59-67.

Sokal, R. R. \& SNeath, P. H. A. (1963). Principles of Numerical Taxonomy. San Francisco: W. H. Freeman.

Stanier, R. Y., Palleroni, N. J. \& Doudoroff, M. (1966). The aerobic pseudomonads: a taxonomic study. Journal of General Microbiology 43, 159-271. 
Whitaker, R. J., Byng, G. S., Gherna, R. L. \& Whitaker, R. J., Byng, G. S., Gherna, R. L. \& JENSEN, R. A. (1981a). Comparative allostery of 3- JENSEN, R. A. (1981b). Diverse enzymological deoxy-D-arabino-heptulosonate 7-phosphate synthetase as an indicator of taxonomic relatedness in pseudomonad genera. Journal of Bacteriology 145, 752-759. patterns of phenylalanine biosynthesis in pseudomonads are conserved in parallel with deoxyribonucleic acid homology groupings. Journal of Bacteriology 147, 526-534. 